\title{
Eye Movements: From Psycholinguistics to Font Design
}

The study of reading has been greatly advanced in the past 40 years by the examination of eye movements recorded during the reading process. Despite the advances made by reading researchers using eye movement recording as a methodology, this research has resulted in relatively few advances in the way text is displayed to readers. That is not to say that textual displays have not undergone significant improvements over this time. Only that the improvements were not driven by eye movement research. This disconnect is of particular interest given the applicability that eye movements offer for understanding all aspects of the reading process. The possible reasons for this disconnect between psycholinguistic research and font design will be discussed. Additionally, current psycholinguistic research trends that overlap with potential font design issues will be explored during a review of the eye movement findings. 


\subsection{Introduction}

Perhaps no experimental methodology has shed more light on the reading process-or offers more promise for continued gains - than eye tracking. This chapter is devoted to the use of eye tracking as a methodology for studying reading, focusing in particular on how this methodology may be useful in guiding decisions on aspects of font design.

Eye movements are a necessary product of the physiology of the retina. The ability to discern fine detail is limited to a small central region of the retina-the fovea. Roughly speaking, the fovea occupies the central two degrees of our vision. At normal reading distances only 6 or 7 letters will fall inside the fovea. This means that for particularly long words at least some of the letters will fall into a region adjacent to the fovea referred to as the parafovea. Our visual acuity, and therefore our ability to discern letter identities, decreases with increasing eccentricity from the fovea (Bouma, 1970; Klein, Berry, Briand, D'Entremont \& Farmer, 1990). Therefore, we must move our eyes when we read in order to place the image of the word we want to identify onto or near to the fovea for efficient processing.

\subsection{Characteristics of reading eye movements}

Despite the illusion that our gaze shifts smoothly across the page while we read, reading eye movements consist of a sequence of saccades separated by brief stops (fixations). This jerky appearance of the eyes can be easily seen by anyone with a page of text and a hole punch. Simply punch a hole in the page and find a willing friend to read the text while you peer through the hole to observe their eyes. In fact, recent research confirms that our eyes make 
saccades between words even in situations in which the text is moving-or scrolling (Valsecchi, Gegenfurtner, \& Schütz, 2013).

The size of a typical saccade in English is about 7-9 characters (Rayner, 2009). However, there is a high degree of variability in the length of reading saccades. Also, the length of reading saccades is determined more by the constraints of the linguistic input (number of letters) than by constraints of the visual system (degree of visual angle) (Morrison \& Rayner, 1981). For instance, readers of Chinese will move their eyes in much smaller saccades (2-3 characters) than readers of English. However, in Chinese, 2 character words are the norm and it's rare to have words composed of 4 characters or more. Therefore, the smaller saccades are required in Chinese reading to prevent the eye from outpacing the minds language comprehension systems. Saccade lengths are also highly sensitive to the spatial extent of text and the oculomotor system is capable of quickly adapting to the typographical environment (Slattery \& Rayner, 2010). So, a wider font that requires longer saccades in order to move from word to word will yield longer average saccade lengths than a narrower font when measured by visual angle even though the number of letters traversed may be roughly the same.

Saccades are considered ballistic eye movements that "fire" from one location to the next. The targeting procedure for saccades a) takes time, and b) is error prone. Estimates on the time to plan and initiate a saccade to a new location are approximately $150-200$ ms (Becker \& Jürgens, 1979; Rayner, Slowiaczek, Clifton, \& Bertera, 1983). The error involved in saccades is assumed to be composed of two components: saccadic range error, and random error (McConkie, Kerr, Reddix, \& Zola, 1988). Saccadic range error refers to the finding that long 
saccades tend to undershoot their intended targets while short saccades tend to overshoot their intended targets with saccadic range error being zero for some idealized saccade length (e.g. 6-7 characters). The random component of saccadic error is assumed to have a mean of zero and a standard deviation that is a function of saccade length being larger for longer than for shorter saccades.

The initial saccade to a word tends to place the eyes in a location just left of word center-the preferred viewing location (Rayner, 1979). However, there is considerable variability in within word fixation locations. In fact, the distributions of within word fixation locations overlap at word boundaries. Therefore, some of the fixations at the beginning of a word $(n)$ were in fact likely intended for the prior word $(n-1)$ and some of the fixations at the end of word $n$ were in fact intended for word $n+1$. These errant fixations are referred to as mislocated fixations (Drieghe, Rayner, \& Pollatsek, 2008; Engbert \& Nuthmann, 2008; Nuthmann, Engbert, \& Kliegl,2005).

Another important property of saccades is that new visual information is not typically encoded during them. Therefore, during saccades we are effectively blind-an effect referred to as saccadic suppression (Matin, 1974). That our minds would suppress the visual information impeding on the retina during a saccade makes intuitive sense since this information would be little more than a blur. In fact, saccadic suppression extends beyond the end of the saccade as vision remains somewhat suppressed at the very beginning of fixations (Bremmer, Kubischik, Hoffmann, \& Krekelberg, 2009; Slattery, Angele, Rayner, 2011). 
For English, reading saccades that travel from left to right are classified as "forward saccades" while those that move from right to left are usually called "regressive saccades". It is estimated that $\sim 10-15 \%$ of eye movements are regressive during normal reading though this number can be higher in difficult reading situations or with novice readers (Rayner, 1998, 2009). Saccades that move the eye from one line of text to another are referred to as return sweeps and are not considered regressive saccades. Return sweeps are an important part of normal reading and one where saccadic error can lead to momentary reading difficulties. No doubt you have occasionally made a return sweep to the wrong line of text while reading. Recovering from such oculomotor errors can be time consuming. Based on this it seems appropriate to follow the basic recommendations of Bouma (1980) that line spacing be adjusted relative to line length so as to keep the angle of the correct return sweep from being too small.

\subsection{Eye movement measures of processing}

The chief measures of processing time are the fixation durations. While legibility effects, or how easy the letters in a word are to encode, should influence the duration of eye fixations, it is quite clear that these durations are largely influenced by the difficulty associated with the lexical processing of the fixated word (Rayner, 1998, 2009). For example, readers spend less time fixating high frequency words than low frequency words (Rayner, 1998, 2009). The word frequency effect is particularly well established having been replicated more times than earl grey tea aboard the Starship Enterprise. 
One obvious measure of processing time is the average fixation duration on a passage of text. While this can be informative it can also be misleading if presented alone because passage reading is composed of a highly variable number of fixations. So, when comparing two fonts, a decrease in average fixation duration could be offset by an increased number of fixations. In such offsetting cases, the relative size of each effect would determine the effect on measures of overall processing like total reading time or reading rate.

Recording eye movements has an advantage over just measuring reading time as researchers can examine oculomotor behavior for specific regions of interest (ROI) within a passage. For reading, the ROI are typically individual word units which are standardly defined as the word and the space prior to it (Rayner, 1998). This standard has made comparison of word processing measures between studies far easier. However, larger ROIs can be useful. For instance, phrases with particular typographical elements (e.g. italics) may be used to examine how changes in these elements influence the natural movement of the eyes. Or, with web page development, the ROIs could be particular advertisements or hyperlinks (Fitzsimmons, Weal, Drieghe, 2014).

Another benefit of eye tracking is that it provides a continuum of processing time measures (Rayner, 1998) For instance, word frequency effects occur very early in word processing with low frequency words eliciting longer first fixation durations than high frequency words. However, alternating case effects first appear in gaze duration (Reingold, Yang, \& Rayner, 2010) which adds the duration of the first fixation with the duration of all immediate refixations. First fixation and gaze duration are both considered measures of early word 
processing while measures like second pass time (the sum of all rereading fixations) reflect late processes related to comprehension difficulty related to word mis-readings (Slattery, 2009) and ambiguity resolution (Ferreira \& Henderson, 1991; Frazier \& Rayner, 1982; Slattery, Sturt, Christianson, Yosida, \& Ferreira, 2013).

Blinks are often viewed as a nuisance variable as they represent a major source of data loss. When the eye is shut we do not know how it is behaving. For this reason, participants in eye movement studies are routinely instructed to minimize their blinking during passage reading and to instead blink just prior to and following each reading trial. This strategy is highly effective when the reading passages are only a sentence long. However, with paragraphs, blinks will be an inevitable part of the data record. For typographical research this might not be a big problem. That is, blinks are also a potentially useful measure of eye fatigue (Stern, Boyer, \& Schroeder, 1994). As the total number of blinks will increase with the length of time it takes someone to read a passage, the appropriate measure for examining typographic effects would be blink rate (blinks per minute). Slattery and Rayner (2010) included an analysis of blink rate in their examination of the ClearType anti-aliasing used by Microsoft. They showed that the benefits of anti-aliasing in terms of reading rate were not accompanied by any increase in eye fatigue as measured by blink rate. As reading from screen increases, the need to assess changes in screen technology may make blink rate an even more important measure.

\subsection{Gaze Contingent Eye Movement Methods}

We have learned a considerable amount about the processes involved in reading by monitoring eye movements while people read static passages of text. In such studies, the texts 
are carefully constructed ahead of time in order to examine how a variable (e.g. word frequency, syntactic structure, contextual constraint) influences eye movements. However, with eye tracking researchers can do so much more. For instance, it is possible to change what is presented on the screen based on where the reader is looking. While the range of manipulations available with gaze contingent display changes is seemingly endless, I will be discussing three techniques that may be valuable in the study of typography.

\subsubsection{Moving window}

The moving window paradigm (McConkie \& Rayner, 1975; Rayner \& Bertera, 1979) presents text to readers in a manner in which the letters outside of a readable "window" are replaced with masking letters. This readable window is tethered to the fixation and therefore moves through the text with the eyes (see Figure 1). In studies using the moving window paradigm, researchers manipulate the size of the window as well as the types of information maintained outside the window. For instance, in the example shown in Figure 1, information about word boundaries (inter-word spaces) are still present outside the readable window but letter identities have been masked with the letter " $x$ " . Using the moving window technique researchers have explored the perceptual span (i.e. the area around fixation from which useful information for reading can be obtained). These studies have found that the perceptual span for reading English is asymmetric, extending 3-4 letter spaces to the left of fixation and 14-15 letter spaces to the right (McConkie \& Rayner, 1975; McConkie \& Rayner, 1976; Rayner \& Bertera, 1979; Rayner, Well, \& Pollatsek, 1980; Rayner, Well, Pollatsek, \& Bertera, 1982; Underwood \& McConkie, 1985; Underwood \& Zola, 1986). The size and asymmetry of the 
perceptual span depends on language characteristics. It is smaller in Chinese (Chen \& Tang, 1998; Inhoff \& Lui, 1998) and the asymmetry is reversed for Hebrew (Pollatsek, Bolozky, Well, \& Rayner, 1981). Additionally, the perceptual span does not extend to upcoming lines of text (Inhoff \& Briihl, 1991; Inhoff \& Topolski, 1992; Pollatsek, Raney, LaGasse, \& Rayner, 1993).

Finally, the perceptual span is not a fixed property; it is smaller for beginning readers compared to skilled readers (Rayner, 1986), for older readers compared to younger readers (Rayner, Castelhano, \& Yang, 2009), and for slower readers compared to faster readers (Rayner, Slattery, Bélanger, 2010). With the moving window technique, researchers could explore the extent to which a typographical element was useful by varying the size of the window around which this element was available. For instance, would the presence of serifs within the moving window increase or decrease the perceptual span?

Figure 1. Moving window illustration

The quick brxxx $x x x \quad x x x x x x \quad x x x x \quad x x x \quad x x x x \quad x x x$. (อ)

Xxx xxxck brown fox jxxxxx xxxx xxx xxxx xxx. (อ)

Xxx xxxxx xxxxx xxx jumped over txx xxxx xxx. (อ)

Xxx xxxxx xxxxx xxx xxxxxx over the lazy xxx. (b)

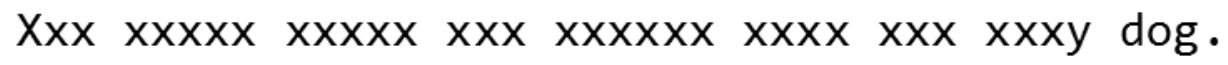
$x x x \operatorname{xxxxx} x x x x x$ fox jumped oxxx $x x x \quad x x x x \quad x x x$. (2)

\subsubsection{Boundary change}


The boundary change paradigm initiates a change to the text only after the eyes cross an invisible boundary (see Figure $2^{3}$ ). This boundary is routinely placed just prior to the interword space preceding some word of interest. The text in the region prior to the change is referred to as the preview and the text after the change is referred to as the target.

Researchers then compare reading time measures on the word of interest for different preview conditions. In Figure 2, the preview and target have different letters but maintain the same vowel consonant structure and basic word shape. The benefit of having an identical preview compared to various non-identical preview conditions is usually on the order of 30-50 ms (Rayner, 1998, 2009).

Figure 2. Boundary change illustration

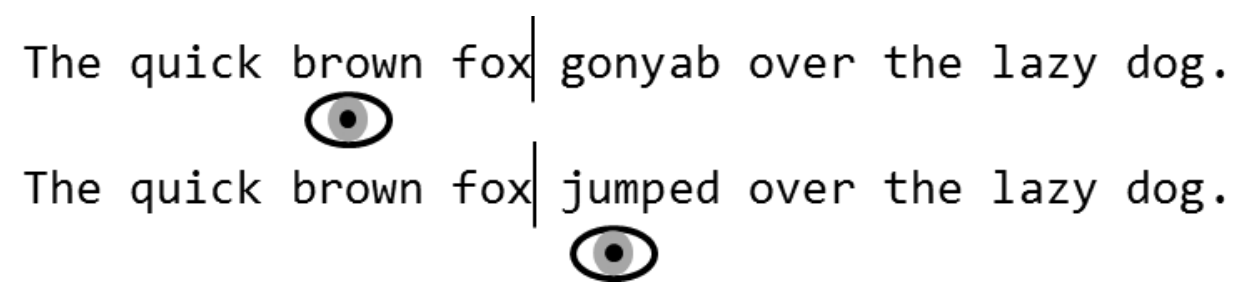

Most research utilizing boundary changes seeks to uncover the representational structure of words that can be processed in the parafovea (for a review see Schotter, Angele, \& Rayner, 2012) and it may be difficult to see how it relates to typography. However, there is one boundary change effect with special significance for font design as it relates to word shape. A recent eye movement study has shown that the upper half of words is more important for reading than the bottom half (Perea, 2012) which may be the result of word shape information. However, transposed letter effects provide strong evidence against the notion that words are recognized by their outline shape alone rather than by their constituent letters (see also Perea 
\& Rosa, 2002). Single word priming studies have also shown that transposed letter non-words are better primes for words than substitution non-words. So, "jugde" is a better prime for the word "judge" than "judpe" (Perea \& Lupker, 2003). Recent boundary change experiments confirm that transposed letter non-words provide greater preview benefit effects during normal reading than substitution letter non-words (Johnson, Perea, \& Rayner, 2007) and the effect is the same whether the transpositions maintain word shape (crown, corwn) or not (clerk, celrk). This would not be the case if word shape was more important than letter identities. Other research has shown that reading requires the individual letters in words be individually discriminable (Pelli, Farell, Moore, 2003; Pelli, Tillman, Freeman, Su, Berger, \& Majad, 2007).

Another important effect revealed by boundary change experiments that is relevant for the more general use of the technique relates to "foveal load". The amount of parafoveal preprocessing a reader can accomplish is inversely related to the difficulty associated with foveal processing (Henderson \& Ferreira, 1990). That is, difficulty processing the currently fixated word results in the focusing of attentional resources to the fovea and away from the parafovea-shrinking the perceptual span. So, when the text is especially difficult due to low frequency words or difficult semantic integration, readers will not get as much useful information from upcoming words. An open question is whether difficult fonts would result in increased foveal load.

\subsubsection{Disappearing text}


Both the moving window and boundary change techniques attempt to implement display changes during saccades so as to take advantage of saccadic suppression. When executed well, subjects are hardly if ever aware that something has happened (but see Slattery, Angele, \& Rayner 2011). However, other display change techniques make no attempt to hide their existence and initiate changes during a fixation. The disappearing text method (Rayner, Liversedge, White, \& Vergilino-Perez, 2003) falls into this category of display changes. It involves removing words from view at varying times after they are fixated. The words reappear only after the eyes move on to another word. What is surprising is that, compared to normal reading, text can be read without much disruption when the words disappear just 60 milliseconds after fixation. Additionally, reader's fixation durations on words are still influenced by word frequency. That is, readers continue fixating the blank region left by the disappearance of a low frequency word for a longer amount of time than they spend fixating the blank region left by the disappearance of a high frequency word (Blythe, Liversedge, Joseph, White, \& Rayner, 2009; Rayner et al., 2003; Rayner, Liversedge, \& White, 2006). While Rayner et al. (2003) only used a 60 millisecond timing for the disappearance, more recent research examining the influence of disappearing text on children (Blythe et al., 2009), and on older readers (Rayner, Yang, Castelhano, \& Liversedge, 2011) used a range of timings. Blythe et al. (2009) revealed that children were only somewhat disrupted by text that disappeared after even the shortest timing tested-40 milliseconds. In stark contrast, Rayner et al. (2011) reported that older readers (65+ years of age) were disrupted significantly more by the disappearing text manipulation than college age readers. However, timings tested included only 
60,50 , and 40 milliseconds. It is possible that at longer delays the disruption experienced by older readers may have been significantly minimized.

There are a few aspects of the disappearing text technique that might make it suitable for investigating typographical factors related to font design. The first is that the timing of the disappearance is assumed to influence the initial visual encoding of words. As long as the text is presented for a duration sufficient for visual encoding, reading can progress normally. If fonts differ in the ease with which they can be encoded then researchers should be able to adjust the duration in order to determine the timing profile of different fonts. Additionally, the disappearing text manipulation has been shown to be sensitive to reader's individual differences (i.e. age) and thus may be useful in determining what font related factors are most important to maximize readability at different ages.

These three gaze contingent display change methods are only the tip of the iceberg. There are many other examples of the general method that have yielded great insight (e.g. fast priming; Sereno \& Rayner, 1992) and new uses occur on a regular basis. These techniques offer creative typographical researchers a wealth of options that remain largely untapped for investigations into font characteristics and page layouts.

\subsection{Eye Movement Studies of Typography}

Given the great success that eye tracking has had for illuminating the cognitive processes related to reading (Rayner, 1998, 2009), it may come as some surprise that there are very few studies of eye movements designed to examine aspects of typography. A google scholar search at the time of this writing using the terms "eye movements" and "reading" 
yielded approximately 124,000 hits. Adding the search term "typography" reduced that number to 964 hits-less than $1 \%$ of the total ${ }^{4}$.

With so much research into the way readers move their eyes, why are so few studies concerned about the influence of typography? Surely there are many factors responsible for the dearth of eye movement studies of typography such as the cost of eye trackers and the expertise required to collect and analyze eye movement data. Additionally, the relevant variables in the design of a font are likely to be strongly interdependent. For instance, when typesetting text, Bouma (1980) argued that longer line lengths require additional interlinear spacing to avoid problems with shallow angled return sweeps. This does not preclude the scientific study of these variables (Tinker, 1963) and their potential interactions but it does make it more complicated and laborious. Given this added level of difficulty it is unsurprising that many early typographical researchers did not tackle the additional challenge of acquiring the expertise needed to collect expensive eye movement data.

So why weren't the Psycholinguists who studied eye movements during reading more interested in the influence of typography? When I was a graduate student in the early 2000s, there seemed to be a common belief that as long as the text was presented in a reasonable manner, a reader's eye movements would be determined more by the characteristics of the language than by differences in the typographic presentation. Along with this belief was the tacit assumption that any difference related to typography would represent a main effect only and would not interact with language variables. So, Times New Roman might be read faster than $\mathbb{O} \mathfrak{I} \mathbb{E} \mathfrak{E}$ grlish but this difference would be the same for all words and sentences. Since 
Psycholinguists were concerned with the processing of the words and sentences, it seemed a safe and simplifying assumption to ignore typography so long as it was held constant within a study. This assumption also had empirical support from an early study utilizing display changes. McConkie and Zola (1979) presented passages of text in aLtErNaTiNg CaSe then on specific saccades the case alternation was switched (AITeRnAtInG cAsE). The astonishing finding was that fixations following a case switch were no longer than fixations that did not follow a switch. The authors conclude that readers integrate abstract letter identities (where ' $A$ ' and ' $a$ ' are the same) from one fixation to the next. If a change in a letters case did not increase fixation durations, it is difficult to imagine that a relatively small change in font would influence such durations. However, as you might guess, reading alternating case is more effortful than reading all lower case or all uppercase text (Juhasz, Liversedge, White, \& Rayner, 2006; Rayner, McConkie, \& Zola, 1980; Reingold, Yang, Rayner, 2010). It may be that alternating case disrupts normal word identification processes (Coltheart \& Freeman, 1974) and that under more normal circumstances changes in fonts would influence fixation durations. Additionally, the foveal load hypothesis predicts that the additional foveal difficulty associated with processing a word written in aLtErNaTiNg CaSe would result in reduced parafoveal processing of upcoming words. This could explain why McConkie and Zola (1979) were unable to find a significant difference between their case switch and no-switch conditions. Still, few Psycholinguists have seemed interested in examining the role of typography.

\subsection{Fonts}


It may be surprising to learn that the most prevalent font family used in eye movement studies of reading is Courier. This has far less to do with Courier's legibility, and far more to do with its fixed width characteristic. In a fixed width font, every letter occupies the same amount of horizontal space. This property has a number of benefits in the eyes of Psycholinguists. First, with a fixed width font controlling the number of letters in target words also controls their physical size. Additionally, fixed width fonts make it easy to implement display changes in moving window and boundary change studies. These experiments would be far more complicated if the letters in the mask or preview were a different size than those in the target. Initiating such changes is possible but would result in perceived changes in the length of the line of text unless the size of the mask or preview letters were made to fit those of the target letters. Rayner, Slattery, and Belanger (2010) conducted such a moving window experiment using both the fixed width font Consolas and the proportional width font Georgia for texts. In order to create the masks needed for the moving window with Georgia, the space between the letters of the mask were adjusted so that the size of the mask would exactly equal the size of the target word that would replace it. They found no significant differences in the size of the perceptual span for the different fonts. Despite similar reading rates for the two fonts across the different window size conditions, there were significant differences in fixation durations and the number of fixations required for reading. The average fixation duration was longer for Georgia, while Consolas required more forward and regressive fixations for reading. The forward saccade differences were due to shorter saccades (measured in characters) for Consolas than for Georgia. In interpreting these differences it is important to note that Georgia has a higher character density than Consolas. So in this study, the higher 
density font led to longer fixation durations but fewer fixations overall compared to the lower density font. The same pattern of effects with respect to density was reported by Kolers, Duchnicky, and Ferguson (1981)-higher density text led to fewer but longer fixations.

While fixed width fonts like Courier and Consolas are preferred by Psycholinguists there are plenty of eye movement studies that use proportional width fonts like Arial and Times New Roman. However, few eye movement experiments have designs that allow for direct font comparisons. One recent study examined how younger and older (65+) readers handle the task of reading a difficult font compared to an easy one (Rayner, Reichle, Stroud, Williams, \& Pollatsek, 2006). They chose Times New Roman as their easy font and OId $\mathbb{E}$ nglisish as their difficult font. One benefit of using these fonts was that they had nearly identical character densities. As predicted, $\mathbb{O} \mathfrak{I} \mathbb{\mathfrak { d }} \mathfrak{E}$ nglish texts took longer to read than Times New Roman ones. This effect was due to an increase in both the average fixation duration and number of fixations for $\mathbb{O} \mathfrak{I} \mathbb{E} \mathfrak{E} n \mathfrak{d} l i \mathfrak{i s h}$ compared to Times New Roman. Moreover, the increased reading time associated with the difficult font was considerably larger for the older readers than for the younger ones. Rayner et al. (2006) also examined the effects of target word frequency and predictability. An analysis of the specific predictability manipulated target words found that when these words were of high ( $86 \%$ cloze completion) predictability, based on prior sentence context, they were fixated for less time than when they were of low ( $4 \%$ cloze completion) predictability. More interesting was the fact that words presented in a difficult font benefitted more from high predictable contexts than words presented in an easy font-font difficulty and word predictability interacted. An analysis of the gaze durations on specific frequency manipulated target words replicated the standard frequency effect. Additionally, the word 
frequency did not interact with the difficulty of the font. That is, low frequency words were fixated for longer amounts of time than high frequency words but the difference between low and high frequency words was similar for both fonts. However, other research utilizing distorted fonts to produce perceptual difficulty found interactions in gaze durations between font distortions and word frequency (Sheridan \& Reingold, 2012). The interactions between lexical and typographical variables are important because they illustrate that typography can influence certain words more than others.

While the font comparisons in Rayner et al. (2006) and Sheridan and Reingold (2012) examined what happens when fonts are made more difficult, other studies have examined the influence of variables designed to make fonts more legible. Slattery and Rayner (2010) conducted a pair of eye movement studies examining Microsoft's ClearType anti-aliasing technique which involves sub-pixel rendering to smooth the outline of letters (see Larson, 2007). Examining ClearType scientifically was aided by clear theoretical predictions. For instance, ClearType should have a larger impact for fonts with more curved or slanted features since these suffer most from aliasing. Consistent with this prediction, they found benefits for ClearType in total time and average fixation duration that interacted with font; effects were larger for Harrington, and Script $\mathcal{M} \mathcal{J}$ than for Times New Roman. So ClearType anti-aliasing improved legibility more for fonts that suffer more aliasing. Based on the shorter fixation duration measures for Times New Roman compared to the other two fonts we could also conclude that it was the more legible font. Additionally, in total time there was an interaction between word frequency and font as Times New Roman had smaller frequency effects than the Harrington, or Script $\boldsymbol{M J}$. Moreover, in gaze duration there was a significant interaction 
between ClearType and word frequency. A second experiment, compared regular, italic, and bold text for two fixed width fonts-Consolas and Andale Mono. Andale Mono was more legible than Consolas as evidenced by shorter gaze durations and total time on target words. Additionally, the italic style was more legible in Andale Mono than Consolas as indicated by interactions in gaze duration and total time. The word frequency effect interacted with style being larger for the italic than for regular or bold text. ClearType also improved the legibility of italic text more than regular or bold text. And there were again indications that word frequency effects were smaller with ClearType anti-aliasing than without it. This complex pattern of effects and interactions is in direct opposition with the tacit psycholinguistic assumption that font differences will have the same influence on all words.

\subsubsection{Serif vs. san serif}

There has also been a renewed interest in using eye movements to explore font characteristics such as the presence or absence of serifs. However, all of these studies have at least one serious flaw that leaves unresolved the question of whether serif or san serif fonts are more legible in general. For instance, Josephson (2008) reported a study that examined two serif fonts (Times New Roman and Georgia) and two san serif fonts (Arial and Verdana). Choosing multiple fonts to estimate the influence of serifs is a plus for this study. Additionally, the study used a within subjects design which is crucial for detecting effects when subject variability is high. However, passages were not counterbalanced across font conditions so the language variables known to influence fixation durations were different for each font. Additionally, only six participants were included in the study and no inferential statistics were 
reported-only condition means. A somewhat improved study was reported by Beymer,

Russell, and Orton (2008). They collected eye movements from 82 adult readers using Georgia and Helvetica. However, they failed to find any significant differences in the eye movement records for the two fonts. They did however report many significant differences between groups of readers. For instance, readers in their 30 s spent more time rereading words than readers in their 50s. Additionally, they found large significant differences between native English readers and readers for whom English was a second language. The flaw in the design of the study was that they manipulated font as a between subject variable. So, 41 subjects read in Georgia and a different 41 read in Helvetica. With large differences between readers, such a design will be severely underpowered to find font differences. More recently, Perea (2013) conducted a much improved study using Lucida and Lucida Sans to address the serif question. The only significant difference between the two fonts was that the serif font received slightly more fixations during reading. However, all other measures were equivalent between the two fonts-including total reading time. The only drawback to the Perea (2013) study was that only one serif and one san serif font were used. Perhaps with a different selection of fonts, serif effects would have been found.

\subsubsection{Inter-letter and inter-word spacing}

Recently there has been an increased interest in exploring the effects of horizontal text spacing. Moreover, this interest spans a number of different subfields within reading research: vision scientists (Arditi, 2004; Arditi \& Cho 2005; Blackmore-Wright, Georgeson, \& Anderson, 2013; Chung, 2002, 2004), psycholinguists (Perea, Moret-Tatay, \& Gomez, 2011; Risko, Lanthier, 
\& Besner, 2011; Slattery \& Rayner, 2013) and typographical researchers (Reynolds \& Walker, 2004).

The spacing between letters influences our ability to discern them (Bouma, 1970;

Chung, Levi, \& Legge, 2001; Erikson \& Erikson, 1974; Marzouki, \& Grainger, 2014). As letters are pushed closer together their identification becomes less accurate. However, identifying a word is different from identifying a letter. With word identification tasks like lexical decision, increases to inter-letter spacing can result in faster reaction times (Perea, \& Gomez 2012), but beyond a critical point additional space slows performance (Chung, 2002; Paterson \& Jordan 2010; Pelli, Tillman, Freeman, Su, Berger, \& Majad, 2007; Vinckier, Qiao, Pallier, Dehaene, \& Cohen, 2011; Risko, Lanthier, \& Besner, 2011). This suggests an optimal inter-letter spacing value at which any change would cause inhibition. This optimal value may differ across readers. When Arditi (2004) allowed low vision researchers to make real time adjustments to various font variables the largest adjustments were made to inter-letter spacing. Additionally, fonts differ widely in their amount of inter-letter space. Perea, Moret-Tatay, and Gomez (2011) noted that the results of studies of spacing are somewhat inconsistent due in part to the use of different fonts. For instance, Perea et al. (2011) manipulated the spacing of Times New Roman and found facilitation for increased inter-letter space while Cohen, Dehaene, Vinckier, Jobert, \& Montavont, (2008) found inhibition for increased inter-letter space using Courier.

In English and other alphabetic languages, word boundaries are signified by an interword space. These spaces benefit reading and reading rate drops when they are removed (Perea \& Acha, 2009; Pollatsek \& Rayner, 1982; Rayner, Fischer, \& Pollatsek, 1998; Rayner, 
Yang, Schuett, \& Slattery, 2013; Sheridan, Rayner, \& Reingold, 2013). The size of inter-word spaces varies across font just as inter-letter space does. Therefore, the benefits of inter-word spaces should differ between fonts based on the size of their inter-word space.

There are now a number of studies which have explored horizontal text spacing on eye movements (Blackmore-Wright, Georgeson, \& Anderson, 2014; Drieghe, Brysbaert, \& Desmet, 2005; Paterson \& Jordan, 2010; Perea, \& Gomez 2012; Perea, Panadero, Moret-Tatay, \& Gomez, 2012; Slattery \& Rayner, 2013; Zorzi, et al. 2012). Most of these studies report benefits to reading from increased spacing. For instance, Perea et al. (2012) found faster reading rates with small increases in inter-letter spacing with Times New Roman. Additionally, these benefits were greater for readers with developmental dyslexia (see also Zorzi et al., 2012). However, in these studies inter-letter spacing was confounded with inter-word spacing. That is, these studies added or removed space between all characters including the inter-word space character. Therefore, they can't separate the influence of one type of spacing from the other.

Another study found detrimental effects of increased spacing on eye movements (Paterson \& Jordan, 2010) when using the fixed width font Courier. However, the smallest addition to inter-letter spacing in their experiment added an extra space b e t w e e $\mathrm{n}$ e a c $\mathrm{h}$ I e t t e $r$ (as in the prior three words) which likely disrupted the overall integrity of the words in the sentences. Paterson and Jordan also reported larger word frequency effects for all increased spacing conditions relative to standard spacing. Their study also manipulated both inter-letter and inter-word spacing but not in a fully factorial manner. Therefore, the individual contributions of each type of space could not be assessed. 
Slattery and Rayner (2013) also manipulated inter-letter and inter-word spacing in two eye movement studies. Their first experiment manipulated spacing between all characters for Cambria and Times New Roman fonts. They found that changing the space between the characters of these fonts increased total reading times. In a follow up study they used a novel manipulation which reduced inter-letter spacing within words then added the saved space to the end of the word thereby increasing inter-word spacing. This condition was then compared to a normal spaced condition for Georgia and Consolas. The adjusted spacing condition yielded shorter gaze durations than standard spacing and this benefit was largely limited to the Georgia font. Blackmore-Wright, Georgeson, and Anderson (2014) also report benefits to reading rate with increased inter-word spaces for readers with macular disease.

More research is needed to explore inter-letter and inter-word spacing. This research should focus on potential interactions between these spacing variables as well as differences in optimal use of space for proportional versus fixed width fonts.

\subsection{Concluding Remarks}

In recent years, eye movement recording in conjunction with appropriate experimental design has helped dispel the assumption that typographical variables can only have a main effect on reading performance. These studies have not only found reliable typographic effects, they have also shown that these effects differ for different words and different readers. The field now seems primed to explore reading from the viewpoint that it represents a complex interplay between language, typographic display, and reader ability. The outcome of such future explorations has the potential to uncover the ways in which font and language variables combine to influence legibility. 


\section{References}

Arditi, A. (2004). Adjustable typography: an approach to enhancing low vision text accessibility. Ergonomics, 47(5), 469-482.

Arditi, A., \& Cho, J. (2005). Serifs and font legibility. Vision research, 45(23), 2926-2933.

Becker, W. W., \& Jürgens, R. R. (1979). An analysis of the saccadic system by means of double step stimuli. Vision Research, 19(9), 967-983. doi:10.1016/0042-6989(79)90222-0

Beymer, D., Russell, D., \& Orton, P. (2008, September). An eye tracking study of how font size and type influence online reading. In Proceedings of the 22nd British $\mathrm{HCl}$ Group Annual Conference on People and Computers: Culture, Creativity, Interaction-Volume 2 (pp. 1518). British Computer Society.

Blackmore-Wright, S., Georgeson, M.A., \& Anderson, S.J. (2013). Enhanced text spacing improves reading performance in individuals with macular disease. PLOS ONE 8(11): e80325. doi:10.1371/journal.pone.0080325

Blythe, H. I., Liversedge, S. P., Joseph, H. L., White, S. J., \& Rayner, K. (2009). Visual information capture during fixations in reading for children and adults. Vision Research, 49(12), 1583-1591. doi:10.1016/j.visres.2009.03.015

Bouma, H. (1970). Interaction effects in parafoveal letter recognition. Nature, 226: 177-178.

Bouma, H. (1980). Visual reading processes and the quality of text displays. IPO Annual Progress Report, 15, 83-90.

Bremmer, F., Kubischik, M., Hoffmann, K., \& Krekelberg, B. (2009). Neural dynamics of saccadic suppression. The Journal Of Neuroscience, 29(40), 12374-12383. doi:10.1523/JNEUROSCI.2908-09.2009 
Chen, H., \& Tang, C. (1998). The effective visual field in reading Chinese. Reading and Writing, 10(3-5), 245-254. doi:10.1023/A:1008043900392

Chung, S. T. L. (2002). The effect of letter spacing on reading speed in central and peripheral vision. Investigative Ophthalmology \& Visual Science, 43: 1270-1276.

Chung, S. T. L. (2004). Reading speed benefits from increased vertical word spacing in normal peripheral vision. Optometry and Vision Science, 81: 525-535.

Chung, S. L., Levi, D. M., \& Legge, G. E. (2001). Spatial-frequency and contrast properties of crowding. Vision Research, 41(14), 1833-1850. doi:10.1016/S0042-6989(01)00071-2

Cohen, L., Dehaene, S., Vinckier, F., Jobert, A., \&Montavont, A. (2008). Reading normal and degraded words: Contributions of the dorsal and ventral visual pathways. Neurolmage, 40: 353-366.

Coltheart, M., \& Freeman, R. (1974). Case alternation impairs word identification. Bulletin of the Psychonomic Society, 3(2), 102-104.

Drieghe, D., Brysbaert, M., \& Desmet, T. (2005). Parafoveal-on-foveal effects on eye movements in text reading: Does an extra space make a difference? Vision Research, 45, 1693-1706.

Drieghe, D., Rayner, K., \& Pollatsek, A. (2008). Mislocated fixations can account for parafovealon-foveal effects in eye movements during reading. The Quarterly Journal of Experimental Psychology, 61(8), 1239-1249. 
Engbert, R., \& Nuthmann, A. (2008). Self consistent estimation of mislocated fixations during reading. PLoS One, 3(2), e1534. doi:10.1371/journal.pone.0001534

Eriksen, B. A., \& Eriksen, C.W., (1974). Effects of noise letters upon the identification of a target letter in a nonsearch task. Perception and Psychophysics, 16, 143-149.

Fitzsimmons, G., Weal, M. J. \& Drieghe, D. (2014) Skim Reading: An Adaptive Strategy for Reading on the Web. In proceedings, of the 6th Annual ACM Web Science Conference held in Bloomington, IN, 23-26 June, (pp. 211-219).

Ferreira, F., \& Henderson, J. M. (1991). Recovery from misanalyses of garden-path sentences. Journal of Memory and Language, 30(6), 725-745. doi:10.1016/0749596X(91)90034-H

Frazier, L., \& Rayner, K. (1982). Making and correcting errors during sentence comprehension: Eye movements in the analysis of structurally ambiguous sentences. Cognitive Psychology, 14(2), 178-210. doi:10.1016/0010-0285(82)90008-1

Henderson, J. M., \& Ferreira, F. (1990). Effects of foveal processing difficulty on the perceptual span in reading: Implications for attention and eye movement control. Journal of Experimental Psychology: Learning, Memory, and Cognition, 16(3), 417-429. doi:10.1037/0278-7393.16.3.417

Inhoff, A. W. \& Liu, W. (1998). The perceptual span and oculomotor activity during the reading of Chinese sentences. Journal of Experimental Psychology: Human Perception and Performance, 24, 20-34. 
Inhoff, A. W., \& Briihl, D. (1991). Semantic processing of unattended text during selective reading: How the eyes see it. Perception \& Psychophysics, 49(3), 289-294. doi:10.3758/BF03214312

Inhoff, A. W., \& Topolski, R. (1992). Lack of semantic activation from unattended text during passage reading. Bulletin of the Psychonomic Society, 30(5), 365-366.

Ito, H., Ogawa, M., Sunaga, S. (2013). Evaluation of an organic light-emitting diode display for precise visual stimulation. Journal of Vision, 13(7):6, 1-21.

Johnson, R. L., Perea, M., \& Rayner, K. (2007). Transposed-letter effects in reading: Evidence from eye movements and parafoveal preview. Journal of Experimental Psychology: Human Perception and Performance, 33(1), 209-229. doi:10.1037/0096-1523.33.1.209

Josephson, S. (2008). Keeping your readers' eyes on the screen: An eye-tracking study comparing sans serif and serif typefaces. Visual Communication Quarterly, 15(1-2), 6779.

Juhasz, B. J., Liversedge, S. P., White, S. J., \& Rayner, K. (2006). Binocular coordination of the eyes during reading: Word frequency and case alternation affect fixation duration but not fixation disparity. The Quarterly journal of experimental psychology, 59(9), 16141625.

Klein, R., Berry, G., Briand, K., D'Entremont, B., \& Farmer, M. (1990). Letter identification declines with increasing retinal eccentricity at the same rate for normal and dyslexic readers. Perception \& Psychophysics, 47(6), 601-606. doi:10.3758/BF03203112 
Kolers, P. A., Duchnicky, R. L., \& Ferguson, D. C. (1981). Eye movement measurement of readability of CRT displays. Human Factors, 23(5), 517-527.

Lagroix, H.E.P., Yanko, M.R., Spalek, T.M. (2012). LCDs are better: Psychophysical and photometric extimates of the temporal characteristics of CRT and LCD monitors. Attention Perception and Psychophysics, 74, 1033-1041.

Larson, K. (2007). The technology of text. IEEE Spectrum, 44, 26-31.

Marzouki, Y., Grainger, J. (2014). Effects of stimulus duration and inter-letter spacing on letterin-string identification. Acta Psychologica, 148, 49-55.

Matin, E. (1974). Saccadic suppression: A review and an analysis. Psychological Bulletin, Vol 81(12), Dec 1974, 899-917.

McConkie, G. W., Kerr, P. W., Reddix, M. D., \& Zola, D. (1988). Eye movement control during reading: I. The location of initial fixations on words. Vision Research, 28, 1107-1118.

McConkie, G. W., \& Rayner, K. (1975). The span of the effective stimulus during a fixation in reading. Perception \& Psychophysics, 17(6), 578-586. doi:10.3758/BF03203972

McConkie, G. W., \& Rayner, K. (1976). Asymmetry of the perceptual span in reading. Bulletin of The Psychonomic Society, 8(5), 365-368.

McConkie, G. W., \& Zola, D. (1979). Is visual information integrated across successive fixations in reading? Perception \& Psychophysics, 25(3), 221-224.

Morrison, R. E., \& Rayner, K. (1981). Saccade size in reading depends upon character spaces and not visual angle. Perception \& Psychophysics, 30, 395-396. 
Nuthmann, A., Engbert, R., \& Kliegl, R. (2005). Mislocated fixations during reading and the inverted optimal viewing position effect. Vision Research, 45(17), 2201-2217. doi:10.1016/j.visres.2005.02.014

Paterson, K. B., \& Jordan, T. R. (2010). Effects of increased letter spacing on word identification and eye guidance during reading. Memory \& Cognition, 38: 502-512.

Pelli, D. G., Farell, B., Moore, D. C. (2003). The remarkable inefficiency of word recognition. Nature, 423: 752-756.

Pelli, D. G., Tillman, K. A., Freeman, J., Su, M., Berger, T. D. \& Majad, N. J. (2007). Crowding and eccentricity determine reading rate. Journal of Vision, 7(2):20, 1-36

Perea, M. (2012). Revisiting Huey: On the importance of the upper part of words during reading. Psychonomic Bulletin \& Review, 19(6), 1148-1153. doi:10.3758/s13423-0120304-0

Perea, M. (2013). Why does the APA recommend the use of serif fonts?.Psicothema, 25(1), 1317.

Perea, M., \& Acha, J. (2009). Space information is important for reading. Vision Research, 49, 1994-2000.

Perea, M., \& Gomez, P., (2012). Increasing interletter spacing facilitates encoding of words. Psychonomic Bulletin \& Review, online DOI 10.3758/s13423-011-0214-6

Perea, M., \& Lupker, S. J. (2003a). Does jugde activate COURT? Transposed-letter similarity effects in masked associative priming. Memory \& Cognition, 31, 829-841. 
Perea, M., Moret-Tatay, C., \& Gomez, P. (2011). The effects of interletter spacing in visual-word recognition. Acta Psychologica, 137: 345-351.

Perea, M., Panadero, V., Moret-Tatay, C., \& Gómez, P. (2012). The effects of inter-letter spacing in visual-word recognition: Evidence with young normal readers and developmental dyslexics. Learning and Instruction, 22(6), 420-430.

doi:10.1016/j.learninstruc.2012.04.001

Perea, M., \& Rosa, E. (2002). Does 'whole-word shape' play a role in visual word recognition? Perception \& Psychophysics, 64(5), 785-794. doi:10.3758/BF03194745

Pollatsek, A., Bolozky, S., Well, A. D., \& Rayner, K. (1981). Asymmetries in the perceptual span for Israeli readers. Brain and Language, 14(1), 174-180. doi:10.1016/0093$934 \times(81) 90073-0$

Pollatsek, A., Raney, G. E., Lagasse, L., \& Rayner, K. (1993). The use of information below fixation in reading and in visual search. Canadian Journal of Experimental Psychology/Revue Canadienne De Psychologie Expérimentale, 47(2), 179-200. doi:10.1037/h0078824

Pollatsek, A., \& Rayner, K. (1982). Eye movement control in reading: The role of word boundaries. Journal of Experimental Psychology: Human Perception and Performance, 8(6), 817-833. doi:10.1037/0096-1523.8.6.817

Rayner, K. (1979). Eye guidance in reading: Fixation locations within words. Perception, 8(1), 2130. 
Rayner, K. (1986). Eye movements and the perceptual span in beginning and skilled readers. Journal of Experimental Child Psychology, 41(2), 211-236. doi:10.1016/00220965(86)90037-8

Rayner, K. (1998). Eye movements in reading and information processing: 20 years of research. Psychological Bulletin, 124: 372-422.

Rayner, K. (2009). The Thirty-fifth Sir Frederick Bartlett lecture: Eye movements and attention in reading, scene perception, and visual search. The Quarterly Journal of Experimental Psychology, 68: 1457-1506.

Rayner, K., \& Bertera, J. H. (1979). Reading without a fovea. Science, 206(4417), 468-469. doi:10.1126/science.504987

Rayner, K., Castelhano, M. S., \& Yang, J. (2009). Eye movements and the perceptual span in older and younger readers. Psychology And Aging, 24(3), 755-760. doi:10.1037/a0014300

Rayner, K., Fischer, M.H.., \& Pollatsek, A. (1998). Unspaced text interferes with both word identification and eye movement control. Vision Research, 38: 1129-1144.

Rayner, K., Liversedge, S. P., \& White, S. J. (2006). Eye movements when reading disappearing text: The importance of the word to the right of fixation. Vision Research, 46(3), 310323. doi:10.1016/j.visres.2005.06.018

Rayner, K., Liversedge, S. P., White, S. J., \& Vergilino-Perez, D. (2003). Reading disappearing text: Cognitive control of eye movements. Psychological Science, 14(4), 385-388. doi:10.1111/1467-9280.24483 
Rayner, K., McConkie, G. W., \& Zola, D. (1980). Integrating information across eye movements. Cognitive Psychology, 12(2), 206-226. doi:10.1016/0010-0285(80)90009-2

Rayner, K., Pollatsek, A., Ashby, J., \& Clifton, C. (2012). The Psychology of Reading. New York: Psychology Press.

Rayner, K., Reichle, E. D., Stroud, M. J., Williams, C. C., \& Pollatsek, A. (2006). The effect of word frequency, word predictability, and font difficulty on the eye movements of young and older readers. Psychology and Aging, 21(3), 448-465. doi:10.1037/0882-7974.21.3.448

Rayner, K., Slattery, T. J., \& Bélanger, N. N. (2010). Eye movements, the perceptual span, and reading speed. Psychonomic bulletin \& review, 17(6), 834-839.

Rayner, K., Slowiaczek, M.L., Clifton, C., \& Bertera, J.H. (1983). Latency of sequential eye movements: Implications for reading. Journal of Experimental Psychology: Human Perception and Performance, 9, 912-922.

Rayner, K., Well, A. D., \& Pollatsek, A. (1980). Asymmetry of the effective visual field in reading. Perception \& Psychophysics, 27(6), 537-544. doi:10.3758/BF03198682

Rayner, K., Well, A. D., Pollatsek, A., \& Bertera, J. H. (1982). The availability of useful information to the right of fixation in reading. Perception \& Psychophysics,31(6), 537550. doi:10.3758/BF03204186

Rayner, K., Yang, J., Castelhano, M. S., \& Liversedge, S. P. (2011). Eye movements of older and younger readers when reading disappearing text. Psychology and Aging, 26(1), 214-223. doi:10.1037/a0021279 
Rayner, K., Yang, J., Schuett, S., \& Slattery, T. J. (2014). The effect of foveal and parafoveal masks on the eye movements of older and younger readers. Psychology and Aging, 29(2), 205-212. doi:10.1037/a0036015

Reingold, E.M., Yang, J., Rayner, K. (2010). The time course of word frequency and case alternation effects on fixation times in reading: Evidence for lexical control of eye movements. Journal of Experimental Psychology: Human Perception and Performance, 36(6), 1677-1683.

Reynolds, L., \& Walker, S. (2004). 'You can't see what the words say': Word spacing and letter spacing in children's reading books. Journal of Research in Reading, 27(1), 87-98. doi:10.1111/j.1467-9817.2004.00216.x

Risko, E. F., Lanthier, S. N., \& Besner, D. (2011). Basic processes in reading: The effect of interletter spacing. Journal of Experimental Psychology: Learning, Memory, and Cognition, 37(6), 1449-1457. doi:10.1037/a0024332

Schotter, E. R., Angele, B., \& Rayner, K. (2012). Parafoveal processing in reading. Attention, Perception, \& Psychophysics, 74(1), 5-35.

Sereno, S. C., \& Rayner, K. (1992). Fast priming during eye fixations in reading. Journal of Experimental Psychology: Human Perception and Performance, 18(1), 173-184. doi:10.1037/0096-1523.18.1.173

Sheridan, H., Rayner, K., \& Reingold, E. M. (2013). Unsegmented text delays word identification: evidence from a survival analysis of fixation durations. Visual Cognition, 21(1), 38-60. 
Sheridan, H., \& Reingold, E. M. (2012). Perceptually specific and perceptually non-specific influences on rereading benefits for spatially transformed text: Evidence from eye movements. Consciousness And Cognition: An International Journal,21(4), 1739-1747. doi:10.1016/j.concog.2012.10.002

Slattery, T.J., (2009). Word misperception, the neighbor frequency effect, and the role of sentence context: Evidence from eye movements. Journal of Experimental Psychology: Human Perception and Performance, 35(6), 1969-1975.

Slattery, T.J., Angele, B., Rayner, K., (2011). Eye movements and display change detection during reading. Journal of Experimental Psychology: Human Perception and Performance, 37, 1924-1938.

Slattery, T. J., \& Rayner, K. (2010). The influence of text legibility on eye movements during reading. Applied Cognitive Psychology, 24(8), 1129-1148.

Slattery, T. J., \& Rayner, K. (2013). Effects of intraword and interword spacing on eye movements during reading: Exploring the optimal use of space in a line of text. Attention, Perception, \& Psychophysics, 75(6), 1275-1292.

Slattery, T.J., Sturt, P., Christianson, K., Yoshida, M., Ferreira, F. (2013). Lingering misinterpretations of garden path sentences arise from competing syntactic representations processing. Journal of Memory and Language, 69(2), 104-120.

Stern, J. A., Boyer, D., \& Schroeder, D. (1994). Blink rate: a possible measure of fatigue. Human Factors: The Journal of the Human Factors and Ergonomics Society, 36(2), 285-297.

Tinker, M. A. (1963). Legibility of print. Ames, lowa: University of lowa Press. 
Underwood, N. R., \& McConkie, G. W. (1985). Perceptual span for letter distinctions during reading. Reading Research Quarterly, 20(2), 153-162. doi:10.2307/747752

Underwood, N. R., \& Zola, D. (1986). The span of letter recognition of good and poor readers. Reading Research Quarterly, 21(1), 6-19. doi:10.2307/747956

Valsecchi, M., Gegenfurtner, K. R., \& Schütz, A. C. (2013). Saccadic and smooth-pursuit eye movements during reading of drifting texts. Journal of Vision, 13(10), doi:10.1167/13.10.8

Vinckier, F., Qiao, E., Pallier, C., Dehaene, S., \& Cohen, L. (2011). The impact of letter spacing on reading: A test of the bigram coding hypothesis. Journal of Vision, 11(6), doi:10.1167/11.6.8

Wang, P., \& Nikolić, D. (2011). An LCD monitor with sufficiently precise timing for research in vision. Frontiers in human neuroscience, 5.

Zorzi, M., Barbiero, C., Facoetti, A., Lonciari, I., Carrozzi, M., Montico, M., \& ... Ziegler, J. C. (2012). Extra-large letter spacing improves reading in dyslexia. PNAS Proceedings Of The National Academy Of Sciences Of The United States Of America, 109(28), 11455-11459. doi:10.1073/pnas.1205566109 


\section{Footnotes}

1. Display change studies require screens capable of changing pixels quickly. Therefore, it is still standard to conduct these studies on CRT screens. However, newer LCD screens are capable of such fast changes (Ito, Ogawa, \& Sunaga, 2013; Lagroix, Yanko, \& Spalek, 2012; Wang \& Nikolic, 2011).

2. Note that the letter ' $x$ ' in the word "fox" is not actually masked in this particular manipulation.

3. The vertical lines in the figure are shown only for description and aren't viewable by readers in such studies.

4. If instead of adding the search term "typography" we add the term "font legibility" or "font readability" the situation is far worse with only 9 and 23 hits respectively.

5. It should be noted that the eye trackers used by Tinker and Paterson were far inferior to those available today both in speed and accuracy. 